\title{
Exames parasitológicos, imunoistoquímicos e histopatológicos para detecçáo de Leishmania chagasi em tecidos esplênicos de cães com leishmaniose visceral
}

\author{
Parasitological, immunohistochemical and histopathological study for Leishmania chagasi \\ detection in spleenic tissues of dogs with visceral leishmaniasis
}

Karen Ingrid Tasca ${ }^{1}$; Wilma Aparecida Starke Buzetti ${ }^{1 *}$; Michely da Silva Tenorio'; Silvana de Cássia Paulan; Flávia Luna Lima ${ }^{1}$; Nina Mari Gual Pimenta de Queiroz ${ }^{1}$; Rosângela Zacarias Machado²;

Tricia Maria Ferreira de Souza Oliveira ${ }^{2}$; Maria Francisca Neves ${ }^{1}$; Antonio Carlos Faconti de Noronha Jr. ${ }^{3}$; Juliana de Assis ${ }^{1}$

${ }^{1}$ Departamento de Biologia e Zootecnia, Faculdade de Engenharia - FEIS, Universidade Estadual Paulista - UNESP

${ }^{2}$ Departamento de Patologia Veterinária, Faculdade de Ciências Agrárias e Veterinárias - FCAV, Universidade Estadual Paulista - UNESP

${ }^{3}$ Centro de Controle de Zoonoses - CCZ, Ilha Solteira - SP, Brasil

Recebido em 31 de Maio de 2008

Aceito em 27 de Fevereiro de 2009

\section{Resumo}

O propósito do presente trabalho foi o estudo da Leishmaniose Visceral Canina - LVC por meio de métodos parasitológicos e imunoistoquímicos para a detecção de formas amastigotas de Leishmania (L.) chagasi em baço, além de descrever a histopatologia das lesóes esplênicas em 34 cães, com diferentes manifestaçóes clínicas da LVC, eutanasiados pelo Centro de Controle de Zoonoses de Ilha Solteira, SP. Esses animais foram examinados clinicamente antes da eutánásia e de acordo com os sinais clínicos da LVC, foram classificados em três grupos: assintomáticos (8 cães), oligossintomáticos (17 cães) e sintomáticos (9 cáes). Após a realização desses exames, dos 34 cães, 22 (64,7\%) estavam positivos e $12(35,3 \%)$ negativos. Desses cães positivos, 1/22 (4,5\%) era assintomático, 12/22 (54,5\%) eram oligossintomáticos e $9 / 22(40,1 \%)$ sintomáticos. Pela histopatologia, os cães, especialmente os sintomáticos apresentavam o baço com inflamação crônica e espessamento na regiáo capsular e trabecular, além de extensa alteração morfológica na polpa vermelha e branca pela presença de grande quantidade de macrófagos repletos de amastigotas, pela reação granulomatosa inflamatória e pelas áreas hemorrágicas. Os exames histopatológicos e a detecçáo microscópica direta da L. (L.) chagasi revelaram que o baço é um órgão útil para auxiliar no diagnóstico da LVC. A coloração imunoistoquímica foi a que detectou o maior número de tecidos esplênicos positivos com amastigotas, além de elucidar os casos suspeitos pelos exames parasitológicos, principalmente, nos animais assintomáticos ou oligossintomáticos.

Palavras-chave: Leishmania (L.) chagasi, Leishmaniose Visceral, cães, baço, imunoistoquímica.

\begin{abstract}
The purpose of this work was a Canine Visceral Leishmaniasis - CVL study by parasitological direct examination of Leishmania (L.) chagasi (imprinting and histological), immunohistochemical test and histopathological analysis using spleen tissues from 34 dogs euthanized by the Zoonotic Disease Control Centre from Ilha Solteira, SP, Brazil. According to the clinical signs, the dogs were divided in three groups: asymptomatics ( $8 \mathrm{dogs})$, oligosymptomatics $(17 \mathrm{dogs})$ and symptomatics $(9 \mathrm{dogs})$. After the accomplishment of all diagnostic tests, 22 dogs were considered positives $(64.7 \%)$ and $12(35.3 \%)$ were negatives to CVL. From these positive dogs, 1/22 (4.5\%) was asymptomatic, 12/22 (54.5\%) were oligosymptomatics and $8 / 22(40.1 \%)$ were symptomatics. The histopathological study in spleen tissues from positive, especially symptomatic dogs, showed a diffuse chronic inflammation with thickness of capsular and trabecular regions and there was extense morphologic alteration of the red and white pulp by the presence of abundant macrophages full with amastigotes, the granulomatous inflammatory reaction and haemorragic areas. The data of this work from histopathologic examination and direct microcopic visualization of $L$. (L.) chagasi showed that the spleen was an useful organ to collect sample tissues for CVL diagnosis. The immunostaining detected the highest number of positive dogs and were considered an important and conclusive method to be used in addition to parasitological methods for CVL, particularly in asymptomatic or oligosymptomatic dogs.
\end{abstract}

Keywords: Leishmania (L.) chagasi, Visceral Leishmaniasis, dogs, spleen, immunohistochemical.

\footnotetext{
*Autor para correspondência: Wilma Aparecida Starke Buzetti

Departamento de Biologia e Zootecnia, Faculdade de Engenharia - FEIS,

Universidade Estadual Paulista - UNESP, Av. Brasil, 56, CEP 15385-000

Ilha Solteira - SP, Brasil; e-mail: starke@bio.feis.unesp.br
} 


\section{Introdução}

As leishmanioses são doenças parasitárias causadas por protozoários da ordem Kinetoplastida, família Trypanosomatidae, gênero Leishmania que acometem o homem e diferentes espécies de mamíferos silvestres e domésticos das regiôes tropicais e subtropicais dos chamados Velho e Novo Mundo (MARZOCHI; MARZOCHI, 1994). O agente etiológico da Leishmaniose Visceral - LV no país é a espécie Leishmania (L.) chagasi.

No ambiente doméstico, o cão (Canis familiaris) é o reservatório envolvido na manutenção do ciclo zoonótico predominante em várias regiooes do país (BRASIL, 2003). O diagnóstico clínico da Leishmaniose Visceral Canina - LVC é precário e complexo, pois os sinais clínicos da doença são variáveis e inespecíficos, comuns a outras enfermidades que acometem o cão. A imunossupressão causada por Leishmania pode gerar infecçóes oportunistas, dificultando do mesmo modo o diagnóstico da LVC (SILVA, 2007).

Dependendo da fase da doença e das condiçóes imunológicas, muitos cães infectados apresentam-se assintomáticos. Entretanto, já foi demonstrado que cães infectados, mesmo assintomáticos, são fontes de infecção para os flebotomíneos e, consequentemente, têm papel ativo na transmissão de Leishmania (PALATNICK DE SOUZA et al., 2001). Naturalmente, tanto a resposta imune humoral como a celular estão envolvidas, e a gravidade e variedade dos sinais clínicos da doença dependem do equilíbrio entre esses dois sistemas (POCAI et al., 1998; FEITOSA et al., 2000). Usando técnicas sorológicas, imunoistoquímicas e reação de sensibilidade tardia, é possível avaliar a característica e o tipo de resposta imune que é envolvida e, dessa forma, definir o estado imune dos cães (NOGUEIRA et al., 2007). Lesóes macroscópicas consistem de leve icterícia, linfadenopatia acentuada, esplenomegalia e hepatomegalia. Pela análise microscópica do linfonodo, baço, medula óssea, fígado, rim, pele e coração, já foi observada uma reação linfo-histioplasmocitária acentuada. Numerosos macrófagos reativos, contendo vacúolos parasitóforos intracitoplasmáticos com estruturas basofílicas sugestivas de formas amastigotas de Leishmania sp., foram visualizados na medula óssea, fígado, baço e linfonodo (KRAUSPENHAR, 2007).

As técnicas sorológicas recomendadas atualmente pelo Ministério da Saúde para o inquérito epidemiológico canino são a Reação Imunofluorescência Indireta - RIFI e o ELISA (BRASIL, 2003). A RIFI ainda é o teste de eleição por reunir uma série de vantagens, como fácil execução, rapidez, baixo custo e, sensibilidade e especificidade adequadas quando comparada a outras técnicas (ALVES; BEVILACQUA, 2004). Já a sensibilidade e a especificidade do ELISA dependem do tipo de antígeno empregado (espécie ou forma evolutiva do parasito) e de mudanças no protocolo experimental padrão (tempo de incubação ou tipos de microplacas utilizadas) (REITHINGER et al., 2002).

Pelos exames parasitológicos, formas amastigotas do parasito podem ser observadas em esfregaços de linfonodo, medula óssea, aspirado esplênico, biópsia hepática e esfregaços sanguíneos corados com corantes de rotina, tais como Giemsa, Wright e
Panótico (BRASIL, 2003). Além disso, existem, atualmente, as técnicas imunoistoquímicas que oferecem a vantagem de aumentar a sensibilidade e a especificidade das técnicas parasitológicas por apresentarem facilidades na execução e alto grau de contraste entre os parasitas e as células hospedeiras (FERRER et al., 1988; TAFURI et al., 2004).

No aspecto imunopatológico, a Leishmania nos cães sintomáticos parece desenvolver um modelo imune caracterizado pela elevada atividade das células B e pela ausência da imunidade celular (SLAPPENDEL, 1988).

Devido ao intenso parasitismo no baço de animais sintomáticos por LVC, esse órgão foi escolhido por alguns autores (BARROUIN-MELO et al., 2004, 2006) como um excelente local para a obtenção de amostras biológicas e assim, ser explorado para a obtenção de material para o diagnóstico da LVC, por métodos parasitológicos, imunoistoquímicos e outros.

O objetivo do presente trabalho foi o estudo da LVC por meio de métodos parasitológicos e imunoistoquímicos para a detecção de formas amastigotas de $L$. (L.) chagasi em baço, além de descrever a histopatologia das lesóes esplênicas em cães, com diferentes manifestaçóes clínicas da doença.

\section{Material e Métodos}

\section{Local e animais}

Esse trabalho foi executado em Ilha Solteira, localizada na região Noroeste do estado de São Paulo, considerada endêmica para LVC. Os cães ( $n=34)$ foram entregues ao Centro de Controle de Zoonoses - CCZ de Ilha Solteira, SP, por se apresentarem naturalmente infectados para LVC (kit Bio Manguinhos, título 1:40). Esses cães foram submetidos à eutanásia pelo CCZ, em cumprimento ao Decreto no 51.838 do Ministério da Saúde do Brasil, de 14 de março de 1963, o qual estabelece que animais domésticos portadores de leishmaniose devem ser submetidos à eutanásia. Para este procedimento os cães foram anestesiados com pentobarbital sódico ( $15 \mathrm{mg} / \mathrm{kg} / \mathrm{iv})$ e ainda em plano anestésico, aplicou-se uma ampola de cloreto de potássio a 19,1\%, por via intravenosa, seguindo as recomendaçóes da Resolução no 714, de 20 de junho de 2002, do Conselho Federal de Medicina Veterinária, que dispóe sobre procedimentos e métodos de eutanásia de animais.

Esses animais, antes de sofrerem a eutanásia foram submetidos a exames clínicos. De acordo com os sinais clínicos da LVC foram separados em três grupos: aqueles com mais de três sinais clínicos característicos para LVC foram classificados como sintomáticos ( $\mathrm{n}=9$ cães), com um a três sinais clínicos, como oligossintomáticos ( $\mathrm{n}=17$ cães) e sem qualquer sinal clínico aparente, como assintomáticos ( $\mathrm{n}=8$ cáes). Os animais compreendiam cães de várias idades, sexo e raças, com a maioria sem raça definida.

Em seguida, esses animais foram novamente examinados para se detectar a presença de anticorpos anti-Leishmania no soro, pelos métodos ELISA e RIFI. 


\section{Exames parasitológicos}

Imprinting - IP: Durante as necrópsias, impressóes de fragmentos de tecidos de baço foram realizadas em lâminas de microscópio, fixadas em metanol e coradas pelo Giemsa. Foram analisados até 100 campos microscópicos na objetiva de 100x e os campos positivos com formas amastigotas foram contados. A intensidade do parasitismo foi graduada da seguinte forma: até $10 \%$ dos campos positivos (+); de 11 a $30 \%(++) ; 31$ a $60 \%(+++) ; 65$ a $100 \%$ $(++++)$. Os tecidos dos animais que não apresentaram amastigotas em nenhum dos campos foram considerados negativos (-).

Exames histológicos - HE: Amostras de tecidos de baço de todos os animais foram coletadas e fixadas em soluçáo de formalina tamponada a $10 \%$ e pH 7,4 , emblocadas em parafina para o exame histológico de rotina e coradas com hematoxilina e eosina (HE). Para avaliaçáo do grau parasitário adotou-se o seguinte procedimento: Tecido negativo: ausência de amastigotas (-). Tecido suspeito (+) quando havia lesóes de fraca intensidade que não permitia uma avaliaçáo conclusiva, ou quando o grau de contraste da coloração não era suficiente para permitir uma visualização perfeita das amastigotas, se presentes. Tecido fracamente positivo $(++)$, quando apenas alguns macrófagos foram visualizados com amastigotas, mas concentrados apenas em algumas áreas. Tecido moderadamente positivo (+++), quando em torno de $50 \%$ do tecido estava comprometido com macrófagos infectados. Fortemente positivo $(++++)$, quando a secção tecidual analisada encontrava-se quase que completamente comprometida, tanto pelas lesōes, quanto pela presença dos macrófagos parasitados.

\section{Exame imunoistoquimico}

A técnica adotada para a imunoistoquímica foi a de Tafuri et al. (2004), da seguinte maneira: lâminas com corte do tecido em parafina foram hidratadas por passagens sucessivas em xilol e álcool, de acordo com a técnica histológica padrão. $\mathrm{O}$ anticorpo primário foi o soro hiperimune de cáes comprovadamente infectados com LVC (RIFI; título $\geq 1: 1280$ ). O anticorpo secundário foi anti-coelho produzido em cabra e biotinilado. O complexo enzimático foi uma solução do Complexo Avidina-Biotina peroxidase (Vectstain ABC kit; Vector Laboratory) e o substrato foi o cromógeno New Red (New Red substrate kit, Vector Laboratory). Os tecidos foram finalmente corados com hematoxilina de Mayer e montados entre lâmina e lamínula. As formas amastigotas presentes nos tecidos coraram-se especificamente na cor vermelho tijolo. O resultado foi apresentado apenas como negativo ou positivo, náo se avaliando a intensidade da imuno-reação.

\section{Resultados e Discussáo}

\section{Positividade dos cáes segundo os sinais clínicos}

Para melhor compreensão dos resultados, os animais foram subdivididos em três grupos, visto que cães infectados podem desenvolver sinais clínicos da LVC resultando em morte, enquanto outros permanecem assintomáticos, ou podem desenvolver um ou mais sinais brandos, sendo classificados como oligossintomáticos. Após a realização dos exames parasitológicos (IP e HE) e imunoistoquímicos, verificou-se que dos 34 animais, $22(64,7 \%)$ eram positivos, 12 (35,3\%) eram negativos. Dentre os cães positivos por esses métodos diagnósticos, 1/22 (4,5\%) era assintomático, 12/22 (54,5\%) eram oligossintomáticos e $9 / 22(40,1 \%)$ sintomáticos. De acordo com Cabral et al. (1998) e Sideris et al. (1999), a maioria dos cães infectados não apresenta nenhum sinal clínico. Isso explica a presença de cães assintomáticos positivos para LVC, na presente pesquisa. A maioria dos cáes pertencia ao grupo oligossintomático, ao contrário dos resultados de Moreira et al. (2007) verificando no baço, positividades de 26,$8 ; 28,0$ e de $34,8 \%$, respectivamente, para cães assintomáticos, oligossintomáticos e sintomáticos em exames histoquímicos.

Na Tabela 1, observa-se que desses 34 cáes, o teste IMIQ diagnosticou como positivo $18 / 33(54,5 \%)$ animais, seguido pelo HE com 17/33 (51,52\%) e pelo IP com 13/27 $(48,15 \%)$. Verificou-se assim que esses três métodos foram bastante semelhantes quanto ao número de cães positivos, no entanto, vale lembrar que pelos exames parasitológicos (IP, Figura 1 ou HE, Figuras 2a, 3a, 4a e 4b), 8 (29,63\%) e $12(36,36 \%)$ cáes foram considerados suspeitos pelos exames IP e HE, respectivamente, pela dificuldade na visualização dos parasitas nos tecidos. Nessas situaçóes, o exame IMIQ (Figuras $2 \mathrm{~b}$ e $3 \mathrm{~b}$ ) contribuiu para concluir o diagnóstico, quer seja positivo ou negativo, com ausência de suspeitos, e isto se deveu à coloração específica das formas amastigotas presentes nos tecidos esplênicos. Esses resultados estão de acordo com vários autores que relataram as técnicas parasitológicas como bastante específicas, mas com a imunoistoquímica oferecendo a vantagem adicional, pelo maior grau de contraste entre os parasitas e as células hospedeiras aumentando a sua sensibilidade e a sua especificidade (FERRER et al., 1988; TAFURI et al., 2004).

Tabela 1. Números e porcentagens de cães positivos, suspeitos e negativos para LVC após a realização de exames parasitológicos (IP e HE) e Imunoistoquímicos - IMIQ. Ilha Solteira, SP, 2008.

\begin{tabular}{|c|c|c|c|c|c|c|c|c|}
\hline \multirow{3}{*}{ Testes } & \multicolumn{8}{|c|}{ Números e porcentagens de cáes } \\
\hline & \multicolumn{2}{|c|}{ Positivos } & \multicolumn{2}{|c|}{ Suspeitos } & \multicolumn{2}{|c|}{ Negativos } & \multirow{2}{*}{ Total } & \multirow{2}{*}{ NR } \\
\hline & No & $\%$ & No & $\%$ & No & $\%$ & & \\
\hline IP & 13 & 48,15 & 8 & 29,63 & 6 & 22,22 & 27 & 7 \\
\hline $\mathrm{HE}$ & 17 & 51,52 & 12 & 36,36 & 4 & 12,12 & 33 & 1 \\
\hline IMIQ & 18 & 54,50 & 0 & 0 & 15 & 45,50 & 33 & 1 \\
\hline
\end{tabular}




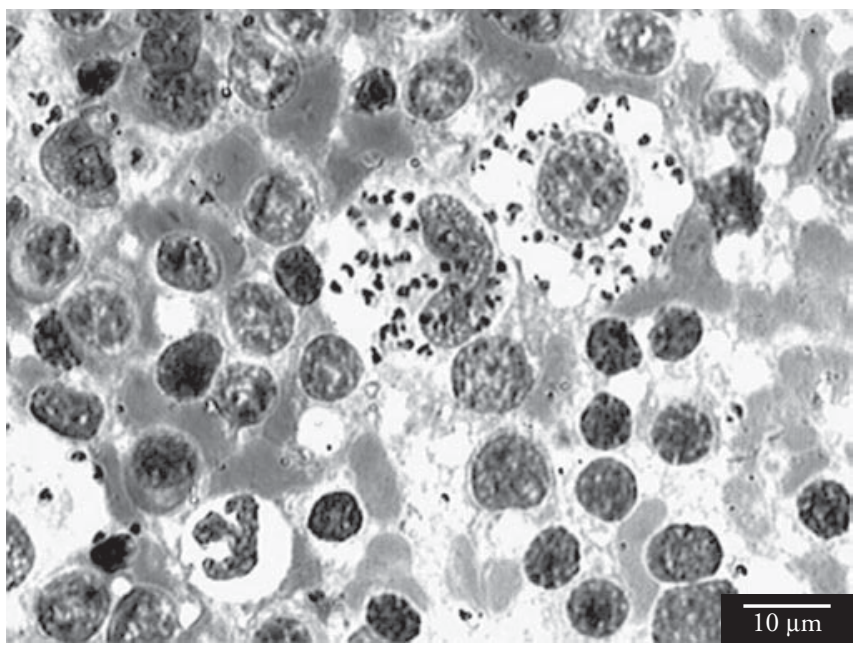

Figura 1. Fotomicrografia do imprinting de fragmentos do baço do cão no 31, sintomático para Leishmaniose Visceral, mostrando dois macrófagos repletos de formas amastigotas de Leishmania. Observe também a presença de algumas amastigotas isoladas pelo material. Giemsa.

\section{Exames parasitológicos, imunoistoquímicos e histopatológicos em tecidos esplênicos}

Cáes assintomáticos: Nesse grupo, apenas 1/8 (12,5\%) cão estava positivo (o cão de no 19 ), resultado esse confirmado por todos os exames realizados, ou seja, os dois parasitológicos e a imunoistoquímica, além também da sorologia (dados não mostrados). Os demais animais, embora 7/8 (87,5\%) tenham sido classificados como suspeitos (+) pelos exames parasitológicos, a imunoistoquímica não detectou nenhuma forma amastigota em seus tecidos e assim foram considerados negativos (Tabela 2). Pela histopatologia do baço, observou-se que o único cão positivo, embora assintomático, apresentava os tecidos hemorrágicos, com vasos dilatados e congestos com aumento no número das arteríolas, inflamação aguda abaixo da cápsula esplênica e polpa branca levemente hiperplásica. Havia também a presença de polimorfonucleares, com predominância de eosinófilos e neutrófilos, além do aumento no número de plasmócitos e macrófagos infectados por Leishmania sp. e focos inflamatórios mononucleares formando granulomas com células gigantes. Nesse cão, o título de anticorpo anti-Leishmania para RIFI (1:1.280) foi alto e o baço estava intensamente $(++++)$ infectado, tanto na histoquímica (HE) como na imunoistoquímica (Tabela 2 e Figuras 2a e 2b). Esse resultado está em concordância com Cabral et al. (1998) e Sideris et al. (1999), onde relataram que nem todos os cães infectados apresentam qualquer sinal clínico da LVC. Pode existir um período assintomático variável, onde os animais podem desenvolver os sinais clínicos posteriormente ou continuar como portadores sãos da leishmaniose canina, mas potenciais transmissores do parasita ao inseto vetor (ABRANCHES et al., 1998). No entanto, o presente cão já soropositivo, teve seu quadro avançado para a manifestação clínica da doença.
Nos demais animais assintomáticos, observou-se em alguns deles, a presença de Babesia sp. em hemácias e pigmentos de hemossiderina e hematina no baço, mas eram suspeitos quanto a presença de formas amastigotas de Leishmania sp., pois, o resultado do parasitológico foi de apenas uma cruz $(+)$.

Cães oligossintomáticos: Dentre os 17 cães oligossintomáticos, 12 estavam positivos $(70,59 \%)$ e $5(29,41 \%)$ negativos. Considerou-se resultado negativo quando os animais eram suspeitos nos exames parasitológicos, ou seja, com apenas uma cruz (+), mas com exame IMIQ negativo (Tabela 3).

Nos tecidos esplênicos dos animais considerados suspeitos, tanto a polpa branca quanto a vermelha apresentavam-se com aparência normal, mas havia em alguns cães, principalmente na região trabecular, grande quantidade de Polimorfonucleares - PMN e, às vezes, acúmulo de macrófagos. No entanto, não se detectava amastigotas nesses locais, ou em algumas vezes, havia apenas a suspeita da presença desses parasitas, pois a coloração histoquímica nem sempre permitia uma boa visualização dos mesmos. Posteriormente, nenhum desses casos suspeitos teve a confirmação positiva pela imunoistoquímica.

Nos tecidos dos baços de cães positivos, com grau parasitário de fraco a moderado $(++\mathrm{a}+++)$, compreendendo apenas $26,7 \%$ dos cães desse grupo, havia hiperplasia de polpa branca, hemorragia e aumento no número de linfócitos e macrófagos, a região trabecular estava espessada e fibrosada, e havia presença de granulaçóes e pigmentos diversos (hematina e hemossiderina) com abundância de PMN. As formas amastigotas de Leishmania sp., principalmente do cão de no 12 (Tabela 3 e Figura 3), encontravam-se isoladas fora das células ou em grandes concentraçóes dentro dos macrófagos, na polpa vermelha, polpa branca, e na região capsular ou subcapsular. Havia também em algumas áreas, a presença de células gigantes.

Em alguns animais foram vistos Babesia sp. nas hemácias. Infecçóes simultâneas com ehrlichioses e babesioses (OLIVEIRA et al., 2008) têm sido observadas em muitos cães e essas doenças podem apresentar quadros clínicos semelhantes aos da LVC e confundir o diagnóstico. Por essa razão, os animais oligossintomáticos foram os mais difíceis de serem analisados.

Em apenas dois cães $(13,3 \%)$ oligossintomáticos, com grau parasitário intenso, observou-se hiperplasia de polpa branca, vasos sanguíneos dilatados, presença de PMN, hematina e hemossiderina. As formas amastigotas de Leishmanias ssp. foram facilmente visualizadas em macrófagos difusamente localizados dentro da cápsula esplênica, na polpa branca e vermelha e também livres nos sinusóides esplênicos. Havia extensas áreas repletas de macrófagos intensamente parasitados com amastigotas, além das células gigantes e de granulomas difusos ou focais. Observou-se ainda uma completa desorganização dos tecidos esplênicos, pela predominância de macrófagos infectados (Figuras 3a e 3b), tanto na polpa branca como na vermelha. A cápsula do baço de alguns animais estava bastante espessada e havia a presença de PMNs.

Cães sintomáticos: Dentre os nove cães sintomáticos, 100\% eram positivos para LVC (Tabela 4). Além das alteraçóes histopatológicas observadas nos baços dos animais oligossintomáticos, como hiperplasia de polpa branca e aumento de macrófagos, plasmócitos e células gigantes, observou-se nos animais 

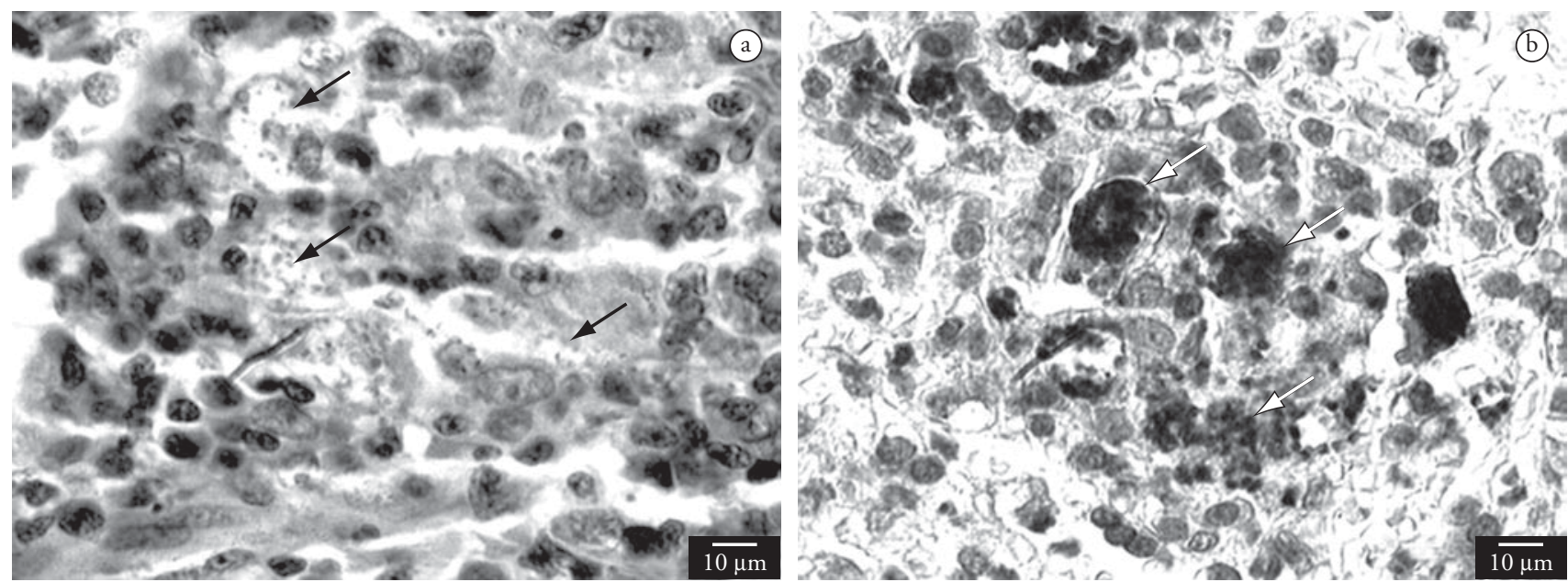

Figura 2. Fotomicrografia de tecido esplênico do cão de no 19 , assintomático para Leishmaniose Visceral, mas apresentando seus tecidos repletos de formas amastigotas do parasita. Amastigotas (setas) visualizadas pela coloração HE, (a) e pela imunoistoquímica (b). Verificar a intensidade do contraste na imunoistoquímica em relação histoquímica.
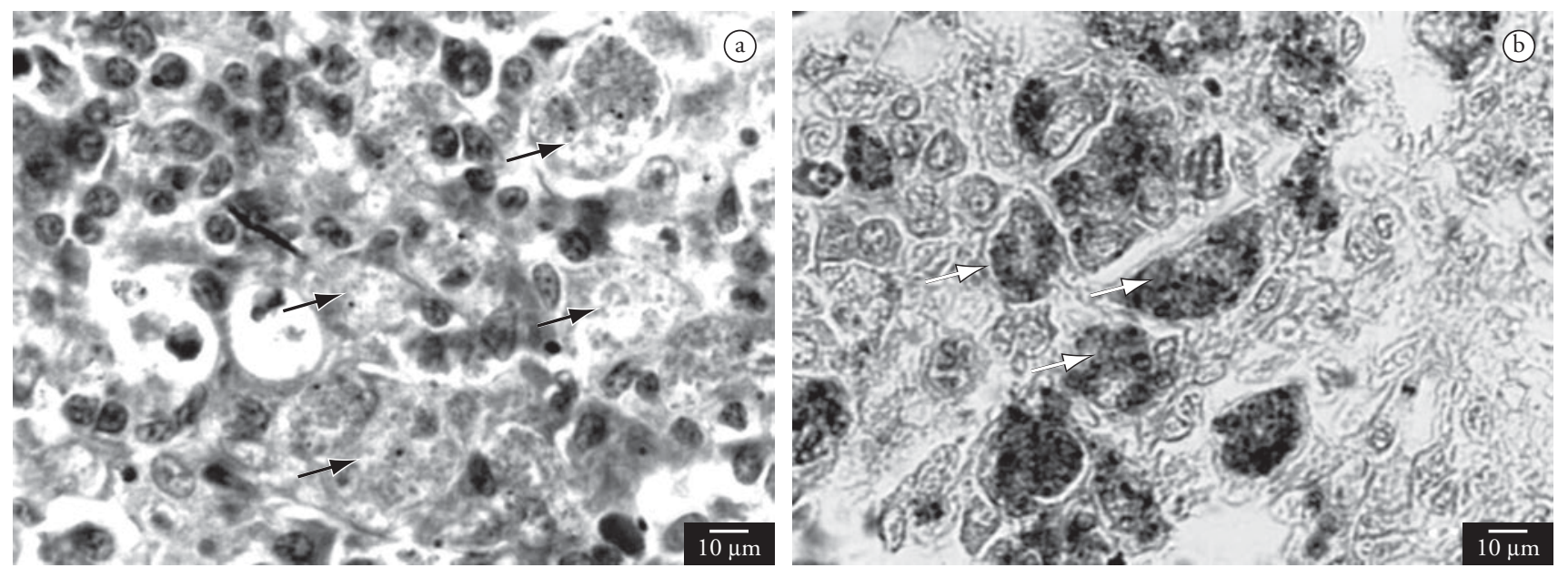

Figura 3. Fotomicrografias de tecido esplênico do cão de no 12, oligossintomático para Leishmaniose Visceral, mas apresentando seus tecidos repletos de formas amastigotas do parasita. Amastigotas visualizadas pela coloração HE (a) e pela imunoistoquímica (b). Verificar a intensidade do contraste na coloração imunoistoquímica em relação à histológica.

intensamente infectados, espessamento do órgão, incluindo a cápsula e as trabéculas esplênicas. $\mathrm{O}$ mesmo foi observado por Tafuri et al. (2001), relatando a hiperplasia da polpa branca com extensa proliferação de macrófagos infectados e algumas célulasgigantes, onde as formas amastigotas estavam presentes dentro dos tecidos esplênicos em $54,5 \%$ dos cães.

Em muitos animais havia intensa proliferação de linfócitos, extensas áreas hemorrágicas e algumas necrosadas. Em alguns cães, os tecidos encontravam-se completamente desestruturados sem a separação nítida da polpa vermelha e branca, com intensa infiltração de macrófagos infectados em todas as regiôes do baço (Figura 4). Tafuri et al. (2001) observaram em um cão, com infecção crônica e já em adiantado estado caquético, o baço com reação inflamatória crônica e difusa estendendo-se desde a região capsular, subcapsular, trabecular e a polpa branca, fato também observado no baço dos cáes sintomáticos do presente trabalho.
Tabela 2. Resultados dos exames parasitológicos pelo imprinting - IP e histológico - HE e pelo imunoistoquímico - IMIQ em tecidos do baço de cáes assintomáticos (A). Ilha Solteira, SP, 2008.

\begin{tabular}{|c|c|c|c|c|}
\hline \multirow{3}{*}{ Cáes } & \multirow{3}{*}{$\begin{array}{l}\text { Sinal } \\
\text { clínico }\end{array}$} & \multicolumn{3}{|c|}{ Tecidos esplênicos de cáes assintomáticos } \\
\hline & & \multicolumn{2}{|c|}{ Parasitológico* } & \multirow{2}{*}{ IMIQ } \\
\hline & & IP & HE & \\
\hline 01 & A & NR & + & $\mathrm{N}$ \\
\hline 02 & A & NR & + & NR \\
\hline 04 & A & NR & + & $\mathrm{N}$ \\
\hline 13 & A & $\mathrm{N}$ & + & $\mathrm{N}$ \\
\hline 18 & A & + & + & $\mathrm{N}$ \\
\hline 19 & A & ++ & ++++ & $\mathrm{P}$ \\
\hline 20 & A & + & $\mathrm{N}$ & $\mathrm{N}$ \\
\hline 22 & A & $\mathrm{N}$ & + & $\mathrm{N}$ \\
\hline
\end{tabular}

*Graus de infecção parasitária; NR: não realizado; $\mathrm{N}$ = negativo; $\mathrm{P}$ = positivo. 


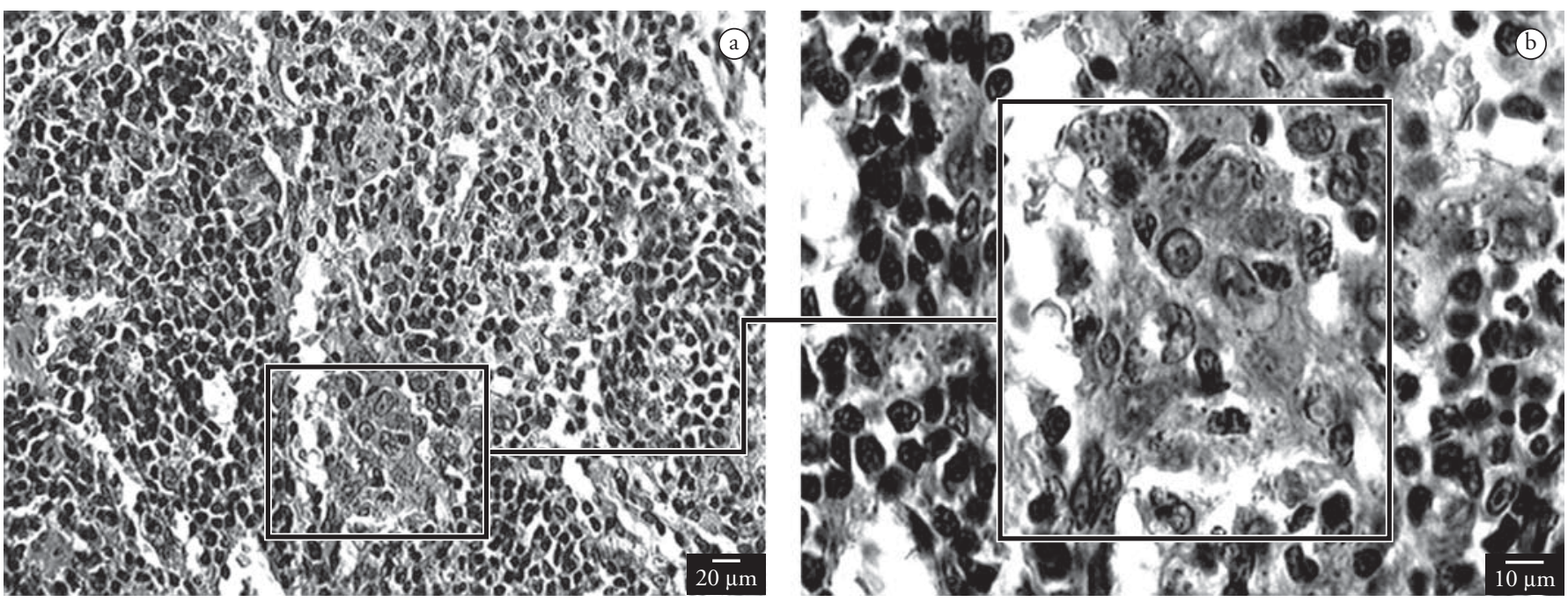

Figura 4. Fotomicrografia das alteraçóes no tecido esplênico do cão de no 30, sintomático para Leishmaniose Visceral, mostrando em áreas da polpa vermelha, abundância de células mononucleares com predominância de macrófagos. Visualizar a presença de amastigotas de Leishmania nos macrófagos presentes na área demarcada (em (a) objetiva de 40x) e no maior aumento em (b) (objetiva de 100x). Técnica histológica e coloração pela HE.

Tabela 3. Resultados dos exames parasitológicos pelo imprinting - IP e histológico - HE e pelo imunoistoquímico - IMIQ em tecidos do baço de cáes oligossintomáticos (O). Ilha Solteira, SP, 2008.

\begin{tabular}{|c|c|c|c|c|}
\hline \multirow{3}{*}{ Cães } & \multirow{3}{*}{$\begin{array}{l}\text { Sinais } \\
\text { clínicos }\end{array}$} & \multicolumn{3}{|c|}{$\begin{array}{c}\text { Tecidos esplênicos de cáes } \\
\text { oligossintomáticos }\end{array}$} \\
\hline & & \multicolumn{2}{|c|}{ Parasitológico* } & \multirow{2}{*}{ IMIQ } \\
\hline & & IP & $\mathrm{HE}$ & \\
\hline 03 & $\mathrm{O}$ & NR & NR & $\mathrm{P}$ \\
\hline 05 & $\mathrm{O}$ & NR & +++ & $\mathrm{P}$ \\
\hline 06 & $\mathrm{O}$ & NR & + & $\mathrm{N}$ \\
\hline 07 & $\mathrm{O}$ & NR & ++ & $\mathrm{P}$ \\
\hline 08 & $\mathrm{O}$ & + & ++ & $\mathrm{P}$ \\
\hline 09 & $\mathrm{O}$ & + & + & $\mathrm{N}$ \\
\hline 10 & $\mathrm{O}$ & + & $\mathrm{N}$ & $\mathrm{P}$ \\
\hline 11 & $\mathrm{O}$ & $\mathrm{N}$ & $\mathrm{N}$ & $\mathrm{N}$ \\
\hline 12 & $\mathrm{O}$ & ++ & +++ & $\mathrm{P}$ \\
\hline 14 & $\mathrm{O}$ & $\mathrm{N}$ & ++ & $\mathrm{N}$ \\
\hline 15 & $\mathrm{O}$ & + & ++ & $\mathrm{P}$ \\
\hline 16 & $\mathrm{O}$ & +++ & + & $\mathrm{P}$ \\
\hline 17 & $\mathrm{O}$ & ++ & + & $\mathrm{N}$ \\
\hline 21 & $\mathrm{O}$ & $\mathrm{N}$ & + & $\mathrm{N}$ \\
\hline 23 & $\mathrm{O}$ & $\mathrm{N}$ & $\mathrm{N}$ & $\mathrm{N}$ \\
\hline 33 & $\mathrm{O}$ & ++ & ++++ & $\mathrm{P}$ \\
\hline 34 & $\mathrm{O}$ & + & ++ & $\mathrm{N}$ \\
\hline
\end{tabular}

*Graus de infecção parasitária; $\mathrm{NR}$ : náo realizado; $\mathrm{N}$ = negativo; $\mathrm{P}=$ positivo.
Além disso, a polpa vermelha mostrava profundas modificaçốes devido à proliferação de macrófagos marginais e a reação inflamatória granulomatosa, onde os macrófagos lotados com amastigotas e com pigmentos de hemossiderina organizavam-se dentro dos granulomas. Já a polpa branca era formada de poucos linfócitos ao redor das arteríolas esplênicas.

Nos animais sintomáticos, somente um cão não foi sororreagente, mas todos os demais apresentaram títulos de anticorpos anti-Leishmania bastante altos tanto para ELISA como para RIFI (dados não mostrados), com tecidos esplênicos fortemente infectados em graus parasitários variando de +++ a ++++ cruzes e positivos na imunoistoquímica. Isso significa que a resposta imune humoral desenvolvida nesses cães não os protegeram contra a infecção, pois esses animais já apresentavam falência dos órgãos linfóides de defesa.

Os exames histopatológicos e a detecção microscópica direta dos parasitas revelaram que o baço é um órgão útil para auxiliar o diagnóstico da LVC. Barrouin-Melo et al. (2006) relataram que $83 \%$ dos cáes soropositivos e $23 \%$ dos soronegativos eram positivos em exames parasitológicos de aspirados obtidos pela punção do baço. Além disso, esse método não estava associado a fatores de risco, e nem tampouco provocava efeitos colaterais e sofrimentos desnecessários aos animais. No presente trabalho, $90,5 \%$ dos animais com sorologia positiva apresentava baços infectados com Leishmania sp.

Embora os animais sintomáticos tenham apresentado um quadro de parasitismo muito intenso no baço, em alguns oligossintomáticos e mesmo assintomáticos, puderam também apresentar um quadro parasitológico bastante semelhante ao observado nos sintomáticos. Por outro lado, nos animais oligossintomáticos, o diagnóstico da LVC tornou-se um pouco mais difícil em função das infecçóes simultâneas com outras enfermidades de sinais clínicos semelhantes dificultando a interpretação dos resultados diagnósticos. 
Tabela 4. Resultados dos exames parasitológicos pelo imprinting - IP e histológico - HE e pelo imunoistoquímico - IMIQ em tecidos do baço de cães sintomáticos (S). Ilha Solteira, SP, 2008.

\begin{tabular}{ccccc}
\hline \multirow{2}{*}{ Cães } & \multirow{2}{*}{$\begin{array}{c}\text { Sinais } \\
\text { clínicos }\end{array}$} & \multicolumn{3}{c}{ Tecidos esplênicos de cáes sintomáticos } \\
\cline { 3 - 4 } & & \multicolumn{2}{c}{ Parasitológico* } & IMIQ \\
\cline { 3 - 4 } 24 & $\mathrm{~S}$ & + & ++ & $\mathrm{P}$ \\
25 & $\mathrm{~S}$ & ++++ & ++++ & $\mathrm{P}$ \\
26 & $\mathrm{~S}$ & ++++ & ++ & $\mathrm{P}$ \\
27 & $\mathrm{~S}$ & +++ & ++++ & $\mathrm{P}$ \\
28 & $\mathrm{~S}$ & ++ & + & $\mathrm{N}$ \\
29 & $\mathrm{~S}$ & ++++ & ++ & $\mathrm{P}$ \\
30 & $\mathrm{~S}$ & ++++ & ++++ & $\mathrm{P}$ \\
31 & $\mathrm{~S}$ & ++++ & +++ & $\mathrm{P}$ \\
32 & $\mathrm{~S}$ & ++++ & +++ & $\mathrm{P}$ \\
\hline
\end{tabular}

${ }^{*}$ Graus de infecção parasitária; $\mathrm{NR}$ : não realizado; $\mathrm{N}$ = negativo; $\mathrm{P}=$ positivo.

Com relação aos testes executados, a coloração imunoistoquímica foi a que detectou o maior número de tecidos esplênicos positivos com amastigotas de L. (L.) chagasi. Além disso, a imunoistoquímica permitiu elucidar os casos suspeitos pelos testes parasitológicos (IP e HE), principalmente nos animais assintomáticos ou oligossintomáticos.

\section{Referências}

ABRANCHES, P.; CAMPINO, L.; SANTOS-GOMES, G. M. Leishmaniose Visceral Canina: Novos conceitos de epidemiologia e imunopatologia e seus reflexos no controle da Leishmaniose Visceral Humana. Acta Médica Portuguesa, v. 11, n. 10, p. 871-875, 1998.

ALVES, W. A.; BEVILACQUA, P. D. Reflexôes sobre a qualidade do diagnóstico da leishmaniose visceral canina em inquéritos epidemiológicos: o caso da epidemia de Belo Horizonte, Minas Gerais, Brasil, 1993-1997. Caderno de Saúde Pública, v. 20, n. 1, p. 259-265, 2004.

BARROUIN-MELO, S. M. et al. Comparison between splenic and lymph node aspirations as sampling methodsfor the parasitological detection of Leishmania chagasi infection in dogs. Memórias do Instituto Oswaldo Cruz, v. 99, n. 2, p. 195-197, 2004.

BARROUIN-MELO, S. M. et al. Can spleen aspirations be safely used for the parasitological diagnosis of canine visceral leishmniasis? A study on asymptomatic and polysymptomatic animals. Veterinary Journal, v. 171, n. 2, p. 331-339, 2006.

BRASIL. Ministério da Saúde. Manual de Vigilância e Controle da Leishmaniose Visceral. Brasília, 2003. 120 p.

CABRAL, M. et al. The immunology of canine leishmaniasis: strong evidence for a developing disease spectrum from asymptomatic dogs. Veterinary Parasitology, v. 76, n. 3, p. 173-180, 1998.
FEITOSA, M. M. et al. Aspectos clínicos de cães com leishmaniose visceral no município de Araçatuba- São Paulo (Brasil). Clínica Veterinária, v. 5, n. 28, p. 36-44, 2000.

FERRER, L. M.; RABANAL, R. M.; DOMINGO, M. Identifications of Leishmania donovani amastigotes in canine tissues by immunoperoxidades staining. Review Veterinary Science, v. 44, p. 2194, 1988.

KRAUSPENHAR, C. Leishmaniose visceral em um canino de Cruz Alta, Rio Grande do Sul, Brasil. Ciência Rural, v. 37, n. 3, p. 907-910, 2007.

MARZOCHI, M. C. A.; MARZOCHI, K. B. F. Tegumentary and visceral leismaniasis in Brazil. Emerging anthropozoonosis and possibilities for their control. Caderno de Saúde Pública, v. 10, supl. 2, p. 359-375, 1994.

MOREIRA, M. A. B. et al. Comparison of parasitological, immunological and molecular methods for the diagnosis of Leishmaniasis in dogs with different clinical signs. Veterinary Parasitology, v. 145, n. 3-4, p. 245-252, 2007.

NOGUEIRA, Y. L.; ODORIZZI, R. M.; NAKAMURA, P. M. A comparison of the immune parameters of dogs infected with visceral leishmaniasis using Western blot and neutralization techniques. Revista Instituto Medicina Tropical, v. 49, n. 6, p. 379-384, 2007.

OLIVEIRA, T. M. F. S. et al. A study of cross-reactivity in serum samples from dogs positive for Leishmania sp., Babesia canis and Ehrlichia canis in enzyme-linked immunosorbent assay and indirect fluorescent antibody test. Revista Brasileira Parasitologia Veterinária, v. 17, n. 1, p. 7-11, 2008.

PALATNICK DE SOUSA, C. B. et al. Impact of canine control on the epidemiology of canine and human visceral leishmaniasis in Brazil. American Journal Tropical Medicine and Hygiene, v. 65, n. 5, p. $510-517,2001$

POCAI, E. A. et al. Leishmaniose visceral (calazar). Cinco casos em Santa Maria, Rio Grande do Sul, Brasil. Ciência Rural, v. 28, n. 3, p. $501-505,1998$

REITHINGER, R.; QUINNNEL, J. R.; DAVIES, A. R. Rapid detection of Leishmania infantum infection in dogs: Comparative study using na imunochromatographic dipstick test, enzime-linked immunosorbent assay, and PCR. Journal of Clinical Microbiology, v. 40, n. 7, p. 2.352-2.356, 2002.

SIDERIS, V. et al. Asymptomatic canine leishmaniasis in Greater Athens area, Greece. European Journal of Epidemiology, v. 15, n. 3, p. 271-276, 1999.

SILVA, F. S. Patologia e patogênese da leishmaniose visceral canina. Revista Trópica - Ciências Agrárias e Biológica, v. 1, n. 1, p. 20, 2007.

SLAPPENDEL, R. J. Canine leishmaniasis. A review based on 95 cases in the Netherlands. Veterinary Quarterly. v.10, n.1, p.16, 1988.

TAFURI, W. L. et al. An alternative immunohistochemical method for detecting Leishmania amastigotes in paraffin-embedded canine tissues. Journal Immunological Methods, v. 292, n. 1-2, p. 17-23, 2004.

TAFURI, W. L. et al. Canine visceral leishmaniose: a remarkable histopathological picture of one case reported from Brazil. Veterinary Parasitology, v. 96, n. 3, p. 203-212, 2001. 